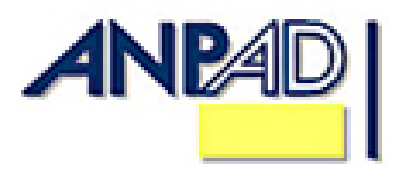
Disponível em
http://www.anpad.org.br/rac
RAC, Rio de Janeiro, v. 18, Edição Especial, art. 3, pp. 41-64, Dezembro 2014
http://dx.doi.org/10.1590/1982-7849rac20141289
(c) EY-No

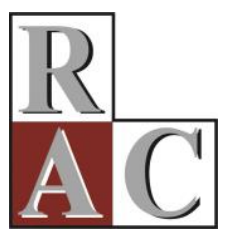

\title{
Capacidades Dinâmicas: O Que São e Como Identificá-las?
}

Dynamic Capabilities: What Are They and How to Identify Them?

Dimária Silva e Meirelles

E-mail: dmeirelles@ gmail.com Universidade Presbiteriana Mackenzie Rua da Consolação, 896, Consolação, 01302907, São Paulo, SP, Brasil.

Álvaro Antônio Bueno Camargo

E-mail: camargo.alvaro@gmail.com

EPCM Gestão de Projetos e Comércio Ltda Av. Irai, 2189, 04082-006, São Paulo, SP, Brasil. 


\title{
Resumo
}

O fenômeno das capacidades dinâmicas nas organizações constitui um ramo de grande interesse para pesquisadores na área de administração, em campos diversos do conhecimento, desde gerenciamento estratégico, empreendedorismo, marketing, gestão de recursos humanos, gestão de operações, até sistema de informação. A partir da a proposta original de Teece, Pisano e Shuen (1997), vários têm sido os esforços teóricos no sentido de desenvolver o conceito de capacidades dinâmicas. Todavia, ao realizar um levantamento desses esforços, constatase uma miríade de definições, algumas até bastante semelhantes, e, principalmente, notam-se fortes controvérsias sobre os condicionantes e os elementos componentes das capacidades dinâmicas. Verifica-se que a evolução do entendimento do que é capacidade dinâmica está associada a dois aspectos fundamentais: elementos componentes e mecanismos pelos quais a empresa desenvolve capacidades dinâmicas. O artigo propõe um modelo integrador das várias definições apresentadas pelos autores pesquisados em que os elementos determinantes da existência de capacidades dinâmicas incluem o conjunto de comportamentos, habilidades, rotinas, processos e mecanismos de aprendizagem e governança do conhecimento, voltados para a mudança e a inovação. Esses elementos são desenvolvidos ao longo da trajetória organizacional, num processo cumulativo de conhecimento e aprendizagem.

Palavras chave: capacidades dinâmicas; competências; habilidades; rotinas; processos.

\begin{abstract}
The phenomenon of dynamic capabilities in organizations is of great interest to researchers in various fields of knowledge in the area of administration, including strategic management, entrepreneurship, marketing, human resource management, operations management, and even information systems. Since Teece, Pisano and Shuen's (1997) original proposal, several theorists have made efforts at developing the dynamic capabilities concept. However, analysis of these efforts shows that there is a myriad of definitions, some quite similar, and there is definite controversy about the conditioning elements and components of dynamic capabilities. Note that the evolution of understanding of what is dynamic capability is associated with two main aspects: components and mechanisms by which a company develops dynamic capabilities. This article proposes an integrative model of the various definitions given by the authors surveyed, in which the determinants of the existence of dynamic capabilities include the set of behaviors, skills, routines, processes and governance mechanisms of learning and knowledge focused on change and innovation. These elements are developed along an organizational trajectory, through a cumulative process of knowledge and learning.
\end{abstract}

Key words: dynamic capabilities; competences; skills; routines; processes 


\section{Introdução}

O estudo das capacidades dinâmicas constitui um ramo afluente nas atividades de pesquisa em administração. De acordo com levantamentos bibliométricos recentes (Barreto, 2010; Stefano, Peteraf, \& Verona, 2010; Vogel \& Gutel, 2013), houve um rápido crescimento dessa literatura nos últimos cinco anos, em campos diversos do conhecimento, desde gerenciamento estratégico, empreendedorismo, marketing, recursos humanos, operações, até sistema de informação. A importância desse conceito reside no fato de que ele trata da capacidade adaptativa da firma frente ao dinamismo do ambiente, ou seja, como as organizações podem alcançar e sustentar vantagens competitivas em um ambiente em mutação (Dosi, Nelson, \& Winter, 2000; Nelson, 1991; Teece \& Pisano, 1994; Teece, Pisano \& Shuen, 1997).

Em termos práticos, o tema capacidade dinâmica ganha relevância sobretudo em mercados cada vez mais globalizados e dinâmicos, em que a mudança tecnológica é rápida e sistêmica (Teece, 2007, 2009). Do ponto de vista téorico, o tema emerge e ganha força na medida em que a manutenção da vantagem competitiva em ambientes complexos e dinâmicos (Teece et al., 1997; Teece \& Pisano, 1994) exige mais que apenas o desenvolvimento de recursos estratégicos e competências internas à firma, tal como proposto pelos autores seminais no campo da Teoria Baseada em Recursos (em inglês, Resource Based View [RBV]), como Wernerfelt (1984), Grant (1991) e Barney (1986).

A abordagem de capacidade dinâmica aponta a importância de se incorporar o papel do dinamismo do ambiente à determinação da vantagem competitiva e, principalmente, o modo como as empresas reagem a esse dinamismo ao longo do tempo (Helfat \& Peteraf, 2009), seja por meio de rotinas (Dosi, Failo, \& Marengo, 2008; Winter, 2003; Zollo \& Winter, 2002) e processos (Bygdas, 2006; Eisenhardt \& Martin, 2000; Teece 2007) ou mesmos por outras capacidades (Collis, 1994; McKelvie \& Davidson, 2009; Pavlou \& El Sawy, 2011; Wang \& Ahmed, 2007; Zahra, Sapienza, \& Davidson, 2006) pelas quais a organização alcança novas configurações de recursos e capacidades (Ambrosini, Bowman, \& Collier, 2009; Helfat \& Peteraf, 2003, 2009; Helfat \& Winter, 2011).

Desde a proposta original de Teece, Pisano e Shuen (1997), vários têm sido os esforços teóricos no sentido de desenvolver o conceito de capacidades dinâmicas. Todavia, ao realizar um levantamento desses esforços, nota-se uma miríade de definições, algumas bastante semelhantes, e, principalmente, observam-se fortes controvérsias sobre os condicionantes (antecedentes) e elementos componentes das capacidades dinâmicas. Alguns autores concentram a análise de capacidades dinâmicas nos aspectos internos da firma. Para estes, a existência de capacidades dinâmicas está relacionada com processos estratégicos e organizacionais (Eisenhardt \& Martin, 2000), ou ainda com a habilidade da firma em desenvolver novas estratégias mais rápido que os concorrentes por meio do reconhecimento de diferentes recursos de valor (Collis, 1994; Teece, 2007).

Outros autores associam a existência de capacidades dinâmicas ao dinamismo do ambiente, ou seja, a ambientes de mutações rápidas e constantes (Teece et al., 1997; Wang \& Ahmed, 2007). Há alguns que focam no desenvolvimento das capacidades, isto é, na trajetória de acumulação de recursos e competências e nos mecanismos e dispositivos que configuram a existência de capacidades dinâmicas (Zollo \& Winter, 2002). Existem empresas que integram, constroem e reconfiguram suas competências mesmo em ambientes pouco dinâmicos e com baixas taxas de mudança (Zollo \& Winter, 2002). Nesse sentido, o importante, na fundamentação de capacidades dinâmicas, é a existência de mecanismos rotineiros que permitam a reconfiguração das capacidades das empresas, ou seja, o uso de mecanismos automáticos de mudanças de capacidades (Winter, 2003).

Nota-se ainda que, para vários autores, as capacidades dinâmicas são resultado de uma combinação de capacidades, ou seja, o construto capacidades dinâmicas seria definido a partir de uma hierarquia de capacidades mais simples e rotinas relacionadas (Andreeva \& Chaika, 2006; Collis, 1994; Wang \& Ahmed, 2007; Winter, 2003). 
Os vários recortes e perspectivas na abordagem de capacidades dinâmicas deram margem a uma série de críticas relacionadas, sobretudo, ao indeterminismo, à tautologia e à própria incoerência de determinados pressupostos (Arend \& Bromiley, 2009). Além disso, por ser uma abordagem eminentemente interdisciplinar (Teece et al., 1997), o tema se confunde com várias outras teorias, principalmente aquelas relacionadas à mudança organizacional, o que reduz o caráter de novidade $\mathrm{e}$ ineditismo típicos de uma nova abordagem (Arend \& Bromiley, 2009).

Em função do exposto, questiona-se, afinal, o que é uma capacidade dinâmica? Quais são seus elementos componentes? Como a firma desenvolve capacidades dinâmicas?

O objetivo deste artigo é apresentar as respostas a essas questões a partir das várias contribuições teóricas já desenvolvidas sobre o tema capacidades dinâmicas, notadamente a partir da análise das definições de capacidade dinâmica, seus elementos componentes e os mecanismos pelos quais as empresas a desenvolvem.

O artigo está estruturado a partir das respostas a essas questões, ou seja, o que são e como identificar as capacidades dinâmicas. São três seções, além desta introdução. Na seção de revisão bibliográfica são apresentadas inicialmente as várias definições e classificações de capacidades dinâmicas. Em seguida, são apresentados os elementos componentes das capacidades dinâmicas e os mecanismos pelo qual se operam essas capacidades. Após a revisão bibliográfica, é proposta uma sistematização dessas.

\section{Revisão Bibliográfica}

A discussão conceitual de capacidades dinâmicas apresentada a seguir está baseada em duas subseções. Na primeira, busca-se responder a questão: o que são as capacidades dinâmicas? Nesse sentido, são apresentadas as várias definições e classificações de capacidades dinâmicas, buscando identificar as semelhanças e os contrapontos entre elas. Na subseção seguinte, busca-se responder a questão: como identificar as capacidades dinâmicas? Para isso, são apresentados os elementos componentes e os mecanismos de desenvolvimento das capacidades dinâmicas apontados nas várias propostas conceituais demonstradas.

\section{Capacidades dinâmicas: o que são?}

O termo Capacidades Dinâmicas é uma tradução aproximada da expressão Dynamic Capabilities em inglês. A palavra capability significa a capacidade ou o poder de fazer algo por meio do uso de competências e habilidades (Oxford University Press, 2010). Uma máquina pode ter certa capacidade de produção, mas não terá a capacidade de produzir algo sem que seja operada por alguém com competência e habilidades para tal. Por isso a palavra capability não deve ser confundida com o conceito de capacidade de produção. Uma indústria pode, por exemplo, ter certa capacidade instalada, mas não poderá produzir se não houver pessoas com habilidades e competências atuando num determinado contexto e fazendo uso de rotinas institucionalizadas na organização.

Na definição inicial proposta por Teece et al. (1997, p. 516), a capacidade dinâmica é definida como a habilidade da firma em integrar, construir e reconfigurar competências externas e internas em ambientes de mudança rápida. As competências são entendidas como o conjunto de rotinas e processos organizacionais (específicos à firma), cujo desempenho é proporcionado pela posse de ativos específicos (difíceis ou impossíveis de imitar). A dinâmica é entendida como situações em que há mudanças rápidas na tecnologia e forças de mercado que exercem efeitos retroalimentadores na firma.

Essa definição inicial é marcada por uma perspectiva fortemente multidisciplinar, que vai além dos limites tradicionais da área de estratégia, incluindo autores de áreas variadas, como inovação e aprendizagem organizacional. De acordo com Teece et al. (1997), os autores de referência são: 
Schumpeter (1942), Penrose (1959/2006), Nelson e Winter (1982), Prahalad e Hamel (1990), Teece (1976, 1986, 1988), Hayes, Wheelwright e Clark (1988), Leonard-Barton (1992) Teece, Rumelt, Dosi e Winter (1994).

Conforme ressaltam Augier e Teece (2008), a estrutura conceitual de capacidades dinâmicas é baseada na combinação de elementos conceituais da visão baseada em recursos (Barney, 1986; Penrose, 1959/2006; Peteraf, 1993; Rumelt, 1984; Wernerfelt, 1984) e da visão neoschumpeteriana da firma (Nelson \& Winter, 1982; Winter, 1964), nas quais se integram as ideias da dinâmica de inovação propostas por Schumpeter (1942) e as de rotinas e competências apresentadas pelos autores da teoria comportamental da firma (Cyert \& March, 1963). De um lado, a força dos recursos estratégicos e competências na geração de um diferencial competitivo (Amit \& Schoemaker, 1993; Barney \& Hesterly, 2011; Grant, 1991; Wernerfelt, 1984). De outro, a evolução e a renovação desses recursos e competências (Collis, 1994; Leonard-Barton, 1992) por meio de rotinas (Winter, 2003). Essa combinação tem como propósito a compreensão tanto da mudança tecnológica quanto da organizacional, a qual é baseada em processos que são moldados tanto pela evolução do ambiente quanto do design organizacional. Neste sentido, a abordagem de capacidade dinâmica é vista como uma potencial integradora da visão de recursos e competências na compreensão não só da criação como também da sustentação da vantagem competitiva das empresas (Lin \& Wu, 2014; Makadok, 2001; Wu, 2010).

De acordo com Teece et al. (1997), a abordagem de capacidades dinâmicas vai além das especificidades das capacidades da firma como fonte de vantagem competitiva. $\mathrm{O}$ foco está no processo pelo qual a firma desenvolve e renova suas competências, processo este que é condicionado tanto pelas escolhas passadas da própria firma como pelo dinamismo do ambiente. Sob essa perspectiva, as capacidades dinâmicas são baseadas no tripé: processos (rotinas ou padrões de práticas correntes e aprendizado), posições (ativos, estrutura de governança, base de consumidores e relações externas com fornecedores e parceiros) e trajetória (histórico de decisões e oportunidades tecnológicas e de mercado). Os processos organizacionais são moldados pela posição da firma em ativos e pela trajetória, a qual define alternativas estratégicas disponíveis. Esses três aspectos determinam a "essência da capacidade dinâmica da firma e a sua vantagem competitiva, ou seja, determinam a sua competência" (Teece et al., 1997, p. 518).

Após essa definição inicial, o conceito de capacidade dinâmica evolui em bases variadas. Ao longo da evolução do tema, notam-se distintos recortes teórico-analíticos, os quais resultam em diferentes concepções do que são capacidades dinâmicas e em como identificá-las, ora marcadas pela ênfase no caráter homogêneo das capacidades (Eisenhardt \& Martin, 2000), ora pelo caráter deliberativo destas (Wang \& Ahmed, 2007; Winter, 2003) e nos seus mecanismos de desenvolvimento (Salvato, 2009; Zollo \& Winter, 2002). Embora haja relacionamento entre essas definições, é comum cada autor enfatizar algum aspecto particular das capacidades dinâmicas (Tabela 1).

Tabela 1

Definições de Capacidade Dinâmica

\begin{tabular}{ll}
\hline Autores & Definição \\
\hline Teece et al. (1997) & $\begin{array}{l}\text { Habilidade da firma em integrar, construir e reconfigurar competências } \\
\text { internamente e externamente, para endereçar ambientes em rápida mudança. }\end{array}$ \\
Collis (1994) & $\begin{array}{l}\text { Capacidade em inovar mais rapidamente ou de forma melhor do que a } \\
\text { concorrência. }\end{array}$ \\
Eisenhardt e Martin (2000) & $\begin{array}{l}\text { Processos da firma que usam recursos para corresponder ou criar mudanças de } \\
\text { mercado. }\end{array}$ \\
\hline
\end{tabular}




\section{Tabela 1 (continuação)}

\begin{tabular}{ll}
\hline Autores & Definição \\
\hline Zollo e Winter (2002) & $\begin{array}{l}\text { Padrão aprendido e estável de atividade coletiva, baseado em mecanismos de } \\
\text { aprendizagem, por meio dos quais a organização sistematicamente gera e } \\
\text { modifica suas rotinas operacionais em busca de melhoria na efetividade. }\end{array}$
\end{tabular}

Winter (2003)

Andreeva e Chaika (2006)

Helfat et al. (2007)

Wang e Ahmed (2007)

Bygdas (2006)

Dosi et al. (2008)

McKelvie e Davidson (2009)

Teece $(2007,2009)$
Capacidades para operar, estender, modificar ou criar capacidades comuns.

Capacidades dinâmicas são aquelas que habilitam a organização a renovar suas competências-chave conforme ocorrem mudanças no ambiente operacional.

Capacidade de uma organização criar, estender ou modificar sua base de recursos propositadamente.

Comportamento constantemente orientado a integrar, reconfigurar, renovar e recriar seus recursos e capacidades e melhorar e reconstruir as capacidadeschave em resposta às mutações do ambiente, para atingir e sustentar a vantagem competitiva.

Processos de ativar estruturas distribuídas de conhecimento e redes fragmentadas de procedimentos e entendimentos soltos que desenvolvem práticas mais eficientes que não são facilmente imitáveis.

Heurísticas gerenciais e as ferramentas de diagnósticos constituem o cerne das capacidades dinâmicas.

Capacidades dinâmicas como um feixe de outras capacidades (capacidades de geração de ideias; de introdução de rupturas no mercado; e capacidades de desenvolvimento de novos produtos, serviços inovadores e novos processos).

Capacidade de sentir o contexto do ambiente; aproveitar oportunidades; gerenciar ameaças e transformações.

No artigo de Eisenhardt e Martin (2000), ao contrário do proposto inicialmente por Teece et al. (1997), a vantagem competitiva é proporcionada pela configuração de recursos e não pelas capacidades. A ênfase no caráter específico das capacidades dinâmicas e no dinamismo do ambiente dá lugar a uma ênfase no caráter homogêneo das capacidades (a sua funcionalidade pode ser duplicada em várias firmas) e na sua variação, conforme o dinamismo do ambiente, não necessariamente empresas que atuam em ambientes dinâmicos possuem capacidades dinâmicas. São fundamentos das capacidades dinâmicas: a capacidade de criar mudanças no mercado e a capacidade de reação às mudanças externas.

Todavia, grande parte dos autores de capacidades dinâmicas enfatizam o diferencial competitivo. Um dos pioneiros a tratar o tema, Collis (1994) define capacidade dinâmica como a capacidade da firma em inovar mais rapidamente ou de forma melhor do que a concorrência. Numa perspectiva mais ampla, que inclui as mudanças em geral, Andreeva e Chaika (2006) associam capacidades dinâmicas às habilidades da organização em renovar suas competências-chave conforme ocorrem mudanças no ambiente no qual a empresa opera.

Mas, na visão de alguns autores, não basta mudar e/ou inovar, é preciso que a mudança seja sistemática e repetitiva, baseada em processos e ou rotinas (Eisenhardt \& Martin, 2000; Winter, 2003; Zollo \& Winter, 2002).

Segundo Winter (2003), para que uma capacidade possa ser considerada dinâmica, a organização deve ser capaz de usá-la de forma repetida e confiável: soluções ad hoc ou talento criativo de pessoas empregadas numa organização não são consideradas capacidades dinâmicas. Uma organização que se adapta de forma criativa a uma sucessão de crises, buscando soluções ao acaso, não está fazendo uso de capacidades dinâmicas. Uma capacidade dinâmica é "um padrão aprendido e estável de atividade coletiva por meio da qual a organização sistematicamente gera e modifica suas rotinas operacionais buscando melhorar sua efetividade" (Zollo \& Winter, 2002, p. 340). 
Conforme definido por Helfat et al. (2007), capacidade dinâmica é a capacidade de uma organização criar, estender ou modificar sua base de recursos propositadamente. Segundo esses autores, o conceito de capacidade dinâmica inclui três funções: (a) identificação de necessidades ou oportunidades de mudança; (b) formulação de respostas adequadas para essas necessidades ou oportunidades; e (c) desenvolvimento de cursos de ação. Observe que esses autores afirmam, porém, que nem todas as capacidades dinâmicas servem às três funções. Existem capacidades dinâmicas que servem para propósitos diferentes. Helfat et al. (2007) colocam também que as capacidades dinâmicas suportam duas funções principais com relação à base de recursos de uma organização: (a) busca, seleção e criação de recursos; e (b) implantação dos recursos.

Também enfatizando a mudança de recursos e as capacidades de forma sistemática, Wang e Ahmed (2007) definem capacidades dinâmicas como o comportamento organizacional constantemente orientado a integrar, reconfigurar, renovar e recriar seus recursos e capacidades e, mais importante, melhorar e reconstruir suas capacidades chave em resposta às mutações do ambiente para atingir e sustentar a vantagem competitiva.

As várias definições de capacidades dinâmicas vão ao encontro daquilo que Helfat et al. (2007) afirmam: as capacidades dinâmicas surgem em diversas formas. Algumas capacidades dinâmicas, por exemplo, permitem que a empresa entre num novo negócio e estenda sua base de negócios, outras capacidades ajudam a empresa a criar novos produtos e processos de produção. Finalmente existem capacidades dinâmicas relacionadas com a capacidade dos gestores em tornar a empresa mais lucrativa e a fazê-la crescer de forma consistente.

Dosi, Faillo e Marengo (2008) colocam que as heurísticas gerenciais e as ferramentas de diagnósticos constituem o cerne das capacidades dinâmicas. A ênfase nas heurísticas gerenciais marca o trabalho mais recente de Teece (2007) sobre capacidades dinâmicas. Partindo da definição inicial de capacidades dinâmicas proposta em Teece et al. (1997), em que estas estão baseadas na habilidade da firma em integrar, construir e reconfigurar competências interna e externamente para endereçar ambientes em rápida mudança, o autor propõe que existem três capacidades de sustentação das capacidades dinâmicas: (a) capacidade de sentir o contexto do ambiente; (b) capacidade de aproveitar oportunidades; e (c) capacidade de gerenciar ameaças e transformações.

A associação de capacidades dinâmicas com a exploração de oportunidades e a geração de ideias também está presente em McKelvie e Davidson (2009). Os autores definem capacidades dinâmicas como um feixe de outras capacidades, como: (a) capacidade de geração de ideias; (b) capacidade de introdução de rupturas de forma a criar dinamismo no mercado no qual a empresa atua; (c) capacidade de desenvolvimento de novos produtos e serviços inovadores em quantidade e qualidade superior em relação aos concorrentes; e (d) capacidade de desenvolvimento de novos processos superiores em relação aos concorrentes.

No âmbito das várias definições de capacidades dinâmicas apresentadas, nota-se que alguns autores advogam a existência de uma hierarquia de capacidades, sendo a capacidade dinâmica o nível mais elevado (Tabela 2). 
Tabela 2

\section{Capacidades Dinâmicas e Hierarquia de Capacidades}

\begin{tabular}{ll}
\hline Autores & Níveis de capacidades \\
\hline Collis (1994) & Nível 1: Capacidades funcionais; \\
& Nível 2: Melhoramento dinâmico dos processos de negócio; e \\
& Nível 3: Capacidade criativa. \\
& Nível 0: Capacidades Operacionais; \\
& Nível Superior: Capacidades Dinâmicas. \\
Winter (2003) & Nível 0: Recursos e capacidades; \\
& Nível 1: Capacidades comuns; \\
Wang e Ahmed (2007) & Nível 2: Capacidades chaves; \\
& Nível 3: Capacidades dinâmicas. \\
\hline
\end{tabular}

Nota. Fonte: Elaborada pelos autores.

Collis (1994) define uma hierarquia de três níveis de capacidades: (a) nível 1: capacidades funcionais, que são as capacidades operacionais que fazem com que a empresa exista; (b) nível 2: capacidades de melhoramento dinâmico dos processos de negócio; (c) nível 3: capacidade criativa ou empresarial; esta última é a que caracteriza a capacidade dinâmica.

Eisenhardt e Martin (2000) afirmam que as capacidades dinâmicas são produto da combinação de capacidades e rotinas simples e relacionadas entre si, algumas das quais podem ser fundamentos de outras e, por isso, devem ser aprendidas primeiro. Da mesma forma, segundo Winter (2003), uma capacidade organizacional é uma rotina de alto nível, ou coleção de rotinas que, junto com o fluxo de entrada, confere à gerência da organização um conjunto de opções para produzir resultados significativos. As capacidades dinâmicas são compostas por conjuntos de rotinas que criam mudanças organizacionais, denominadas rotinas de busca (Nelson \& Winter, 1982).

Winter (2003) classifica as capacidades organizacionais em capacidades de nível zero (capacidades operacionais) e capacidades de nível superior, nas quais se encontram as capacidades dinâmicas. Uma organização baseada apenas em suas capacidades operacionais não cria mudanças. Trata-se de uma organização que sobrevive vendendo o mesmo produto ou serviço para a mesma população de clientes, sem capacidade de realizar alterações em suas rotinas. Esse tipo de organização não evolui e não apresenta um diferencial que confira uma vantagem competitiva. Na medida em que a organização consegue mudar seus procedimentos, gerando novos processos, novos produtos e novos serviços, e ampliando a escala ou a base de clientes servidos, ela possui capacidades dinâmicas. A existência desse conjunto de capacidades dinâmicas é que permite que a empresa mantenha um desempenho superior no longo prazo.

Além destes três níveis, Wang e Ahmed (2007) reforçam a importância de um nível inicial, constituído pelos recursos e capacidades que dão os fundamentos para a existência da firma. Nesse sentido, os autores propõem quatro níveis hierárquicos: (a) nível 0: recursos e capacidades; (b) nível 1: capacidades comuns, relativas à produção de produtos e execução de serviços seus serviços, por meio da combinação de recursos e capacidades; (c) nível 2: capacidades-chave, referem-se ao conjunto de recursos e capacidades que resultam em vantagem competitiva no curto prazo, isto é, num dado momento do tempo; e (d) nível 3: capacidades dinâmicas. Na visão desses autores, embora recursos valiosos, raros, inimitáveis e não substituíveis possam constituir elementos de vantagem competitiva em mercados dinâmicos, essa vantagem não persiste ao longo do tempo. Sempre existe a possibilidade de que as capacidades-chave de uma empresa se tornem obsoletas. Mas, se a empresa tem a capacidade de perseguir a renovação, reconfigurar e recriar seus recursos, suas capacidades comuns e suas capacidades-chave, de forma a endereçar as mudanças ambientais, então, essa capacidade, que é de terceira ordem, é uma capacidade dinâmica. 
Em resumo, as definições de capacidades dinâmicas envolvem esforços de mudança e inovação, esforços estes relacionados a busca, criação, integração, renovação, recriação ou reconfiguração, seleção e implantação de recursos (Helfat et al., 2007), habilidades e competências (Teece et al., 1997) ou capacidades (Wang \& Ahmed, 2007). O resultado desses esforços vai desde a identificação de necessidades ou oportunidades de mudança e geração de ideias; desenvolvimento de novos produtos, serviços e processos superiores em relação aos concorrentes; até a introdução de rupturas, de forma a criar dinamismo no mercado (McKelvie \& Davidson, 2009; Teece, 2009). São respostas e cursos de ação que permitem a empresa entrar num novo negócio, estender sua base de negócios, ser mais lucrativa e crescer de forma consistente (Helfat et al., 2007).

A existência de uma hierarquia de capacidades, as quais resultam numa capacidade dinâmica, levanta críticas relativas ao indeterminismo e à tautologia do conceito (Arend \& Bromiley, 2009). Afinal, capacidade determina capacidade? Quais são os elementos componentes das capacidades dinâmicas? É possível identificá-los? De que forma?

Conforme assinalam Zollo e Winter (2002), sabe-se o que é, mas não se sabe como as empresas desenvolvem capacidades dinâmicas. Na visão destes autores, a capacidade dinâmica de uma organização é baseada em mecanismos de aprendizagem que permitem a constante evolução do conhecimento organizacional, uma dedicação sistemática aos processos de melhorias. Nesta mesma perspectiva de articulação do conhecimento, Bygdas (2006) define as capacidades dinâmicas como processos de ativar estruturas distribuídas de conhecimento e redes fragmentadas de procedimentos e entendimentos soltos para desenvolvimento de práticas mais eficientes que não são facilmente imitáveis. Mas, então, em que consistem esses mecanismos? Como ativá-los?

A seguir são apresentados os elementos componentes e os mecanismos de desenvolvimento das capacidades dinâmicas, a partir dos autores selecionados.

\section{Capacidades dinâmicas: como identificá-las?}

Em linhas gerais, é possível identificar nas várias definições de capacidades dinâmicas aqui apresentadas três elementos componentes: (a) conjunto de comportamentos, capacidades e habilidades (individuais e organizacionais); (b) rotinas e processos; e (c) mecanismos de aprendizagem e governança do conhecimento.

No grupo de autores que tratam as capacidades dinâmicas como conjunto de comportamentos, capacidades e habilidades (Tabela 3), destacam-se as visões de Collis (1994), Andreeva e Chaika (2006), Wang e Ahmed (2007), Helfat et al. (2007) e McKelvie e Davidson (2009). Em linhas gerais, são apontadas capacidades e habilidades relativas ao protagonismo (individual e organizacional), seja no sentido de aprender e exercer a liderança (Andreeva \& Chaika, 2006), seja no sentido de empreender, por meio da identificação de oportunidades (Wang \& Ahmed, 2007), da geração de ideias (McKelvie \& Davidson, 2009), da percepção de mudanças necessárias e da implementação dessas mudanças (Andreeva \& Chaika, 2006; Helfat et al., 2007). 
Tabela 3

\section{Visão das Capacidades Dinâmicas como Comportamentos, Habilidades e Capacidades Organizacionais}

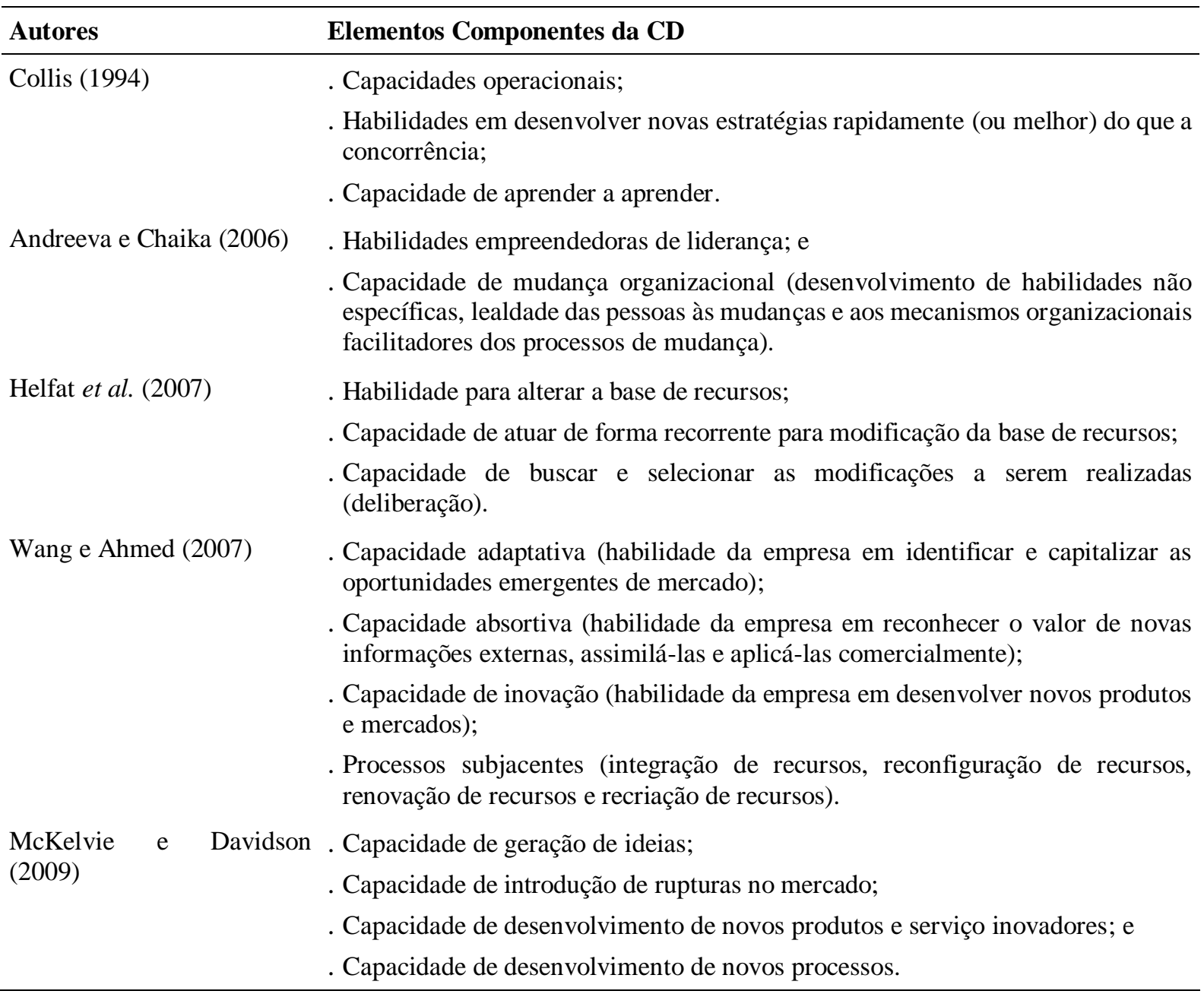

Nota. Fonte: Elaborada pelos autores.

Andreeva e Chaika (2006) enfatizam que a capacidade de mudança é central para a existência de capacidades dinâmicas. Esta capacidade, na visão das autoras, está alicerçada em três pontos chaves essenciais, relativos às habilidades e aos comportamentos individuais e aos mecanismos organizacionais.

Do ponto de vista das habilidades, segundo Andreeva e Chaika (2006), há que se desenvolver habilidades não específicas, isto é, habilidades profissionais adjacentes, não necessariamente ligadas às atividades operacionais cotidianas das pessoas na organização. Como exemplo, as autoras citam as habilidades de autoaprendizagem, comunicação, negociação, resolução de conflitos, liderança, análise econômica de ideias, apresentação de ideias, resolução de problemas, gerenciamento de projetos e pessoas.

Em relação ao comportamento, o aspecto-chave é o desenvolvimento de lealdade das pessoas à mudança, a qual está relacionada com a normalidade pela qual as mudanças são encaradas pelos colaboradores da empresa. Uma das formas de desenvolver essa lealdade é fazer uso de comunicações abertas e transparentes, permitindo diálogos francos e o consequente feedback (Andreeva \& Chaika, 2006). 
Do ponto de vista dos mecanismos organizacionais relevantes, que proporcionam agilidade e eficácia nos processos de mudanças, Andreeva e Chaika (2006) destacam o estabelecimento de grupos de trabalhos multidisciplinares, comitês, delegação de responsabilidades, intensificação da troca de informações entre departamentos e alinhamento do sistema de recompensas com a capacidade de mudar.

Com uma ênfase maior no nível das habilidades organizacionais, Wang e Ahmed (2007) apontam para as habilidades que dão suporte às três capacidades componentes das capacidades dinâmicas: (a) capacidade adaptativa (habilidade da empresa em identificar e capitalizar as oportunidades emergentes de mercado); (b) capacidade absortiva: habilidade da empresa em reconhecer o valor de novas informações externas, assimilá-las e aplicá-las para fins comerciais); e (c) capacidade de inovação (habilidade da empresa em desenvolver novos produtos e mercados por meio da orientação do alinhamento estratégico para comportamentos e processos de inovação).

Na concepção de Wang e Ahmed (2007), a reunião dessas três capacidades e suas respectivas habilidades revela o forte componente tácito da capacidade dinâmica. Quando se fala de capacidades dinâmicas, a questão é a capacidade da organização em empregar recursos, usualmente de forma combinada, e encapsular tanto os processos explícitos como os elementos tácitos, como, por exemplo, know how e a liderança embutida nos processos, de forma a criar uma vantagem competitiva difícil de ser copiada ou imitada. Nesse sentido, os autores destacam que as capacidades dinâmicas não são processos normais, que podem ser codificados, passíveis de serem transferidos mais facilmente entre unidades da organização ou entre organizações. As qualidades que constituem as capacidades dinâmicas refletem um processo de desenvolvimento de habilidades ao longo do tempo, ou seja, é função de sua trajetória temporal. Isso vale tanto ao que se refere à adaptação no tempo certo (capacidade adaptativa), ou ao uso do conhecimento externo em função do nível anterior de conhecimento (capacidade absortiva).

A ênfase no processo adaptativo está presente no grupo de autores que tratam as capacidades dinâmicas como rotinas e processos (Tabela 4). Entretanto, nota-se que, para alguns, como Eisenhardt e Martin (2000), os processos que constituem as capacidades dinâmicas são passíveis de decodificação e replicação, o que torna as capacidades dinâmicas homogêneas, e, portanto, passíveis de imitação. Na visão destes autores, as capacidades dinâmicas são processos de negócio da firma, utilizados para corresponder ou até mesmo criar mudanças de mercado. São exemplos desses processos: rotinas de desenvolvimento de produtos; capacidade de forjar alianças e fazer aquisições; rotinas de alocação de recursos e transferência e replicação de conhecimento.

Tabela 4

\section{Visão das Capacidades Dinâmicas, como Rotinas e Processos}

\begin{tabular}{ll}
\hline Autores & Elementos componentes \\
\hline Eisenhardt e Martin (2000) & $\begin{array}{l}\text { Processos ou rotinas organizacionais e estratégicas pelas quais a organização alcança } \\
\text { novas configurações de recursos. }\end{array}$ \\
Zollo e Winter (2002) & $\begin{array}{l}\text { Processos de acumulação de experiências; articulação de conhecimento; codificação } \\
\text { de conhecimento. }\end{array}$ \\
Winter (2003) & Rotinas de alto nível, que definem padrões de atividades; \\
& . Comprometimento de longo prazo de recursos especializados; \\
& . Exercício de uso das capacidades dinâmicas; \\
& . Investimentos em aprendizagem. \\
. Conhecimento prévio significativo; & . Unidades de processamento de conhecimento; \\
Bygdas (2006) & Redes de conexão das unidades de processos; \\
. Estruturas de conhecimento; \\
. Processos de ativação.
\end{tabular}




\section{Tabela 4 (continuação)}

\begin{tabular}{|c|c|}
\hline Autores & Elementos componentes \\
\hline Dosi et al. (2008) & $\begin{array}{l}\text { Estruturas organizacionais específicas; } \\
\text { Estruturas cognitivas e níveis de aspiração compartilhados; } \\
\text {. Posição da empresa na cadeia de valor e relações com fornecedores e clientes; } \\
\text {. Trajetória de mudanças ao longo do tempo; } \\
\text {. Domínio persistente do equilíbrio entre exploration e exploitation. }\end{array}$ \\
\hline Teece (2007) & $\begin{array}{l}\text { Rotinas e processos de suporte à geração de novas ideias, novos produtos e } \\
\text { serviços, bem como na seleção e na implementação da mudança: } \\
\text { Desenvolvimento científico e tecnológico (fontes internas e externas); } \\
\text {. Identificação de segmentos de mercado alvo; } \\
\text { Soluções para clientes e desenho do modelo de negócios; } \\
\text {. Definição de fronteiras da organização; } \\
\text {. Definição e uso rotineiro de protocolos de tomada de decisões de investimento; } \\
\text { Solução do problema de agência e influência de grupos internos da empresa; } \\
\text {. Descentralização de decisões por meio da decomposição de estruturas } \\
\text { organizacionais; } \\
\text { Coespecialização de ativos. }\end{array}$ \\
\hline
\end{tabular}

Nota. Fonte: Elaborada pelos autores.

Em contrapartida, para outros autores, como Zollo e Winter (2002), Winter (2003) e Dosi et al. (2008), a capacidade dinâmica, embora relacionada à capacidade de replicação de um conjunto de rotinas, é específica ao processo evolucionário da organização, expresso na sua trajetória.

De acordo com Dosi et al. (2008), a capacidade dinâmica está fortemente fundamentada em processos organizacionais estabelecidos por meio de estruturas organizacionais específicas e na existência de estruturas cognitivas e em níveis de aspiração compartilhados e percebidos pelas integrantes da empresa, sendo que a capacidade dinâmica consiste justamente em quebrar ou redistribuir rotinas entre essas estruturas. Outrossim, a capacidade dinâmica está associada à posição da empresa em relação à sua cadeia de valor e à sua relação com fornecedores e clientes.

Na visão de Dosi et al. (2008), o domínio persistente do dilema entre fazer novas descobertas de oportunidades (exploration) ou de aproveitar as oportunidades e aumentar a eficiência daquilo que a empresa já faz (exploitation) é um aspecto fundamental da capacidade dinâmica. Esse domínio pode ser melhor compreendido por meio dos vários processos listados por Teece (2007) na descrição das capacidades componentes das capacidades dinâmicas, que são: sentir o contexto do ambiente; aproveitar oportunidades; gerenciar ameaças e transformações.

De acordo com Teece (2007), a capacidade de sentir o contexto do ambiente no qual a empresa opera está relacionada com a existência de quatro processos: (a) processos para dirigir trabalhos internos de pesquisa e desenvolvimento; (b) processos de exploração de fornecedores para complementar as inovações da organização; (c) processos para explorar desenvolvimentos científicos e tecnológicos exógenos; e (d) processos para identificar segmentos de mercado alvo, para mudar os hábitos dos clientes e para gerar inovações que sejam de interesses destes mesmos clientes.

Já a capacidade de aproveitar oportunidades é, segundo Teece (2007), baseada em quatro componentes: (a) soluções para o cliente; (b) seleção das fronteiras organizacionais; (c) rotinas para seleção de protocolos de tomada de decisões; e (c) rotinas para construir lealdade de comprometimento.

O primeiro componente envolve aspectos relacionados ao modelo de negócio, como: entrega de valor para o cliente, tecnologias e características que devem ser introduzidas no produto ou serviço; 
receita e estrutura de custo de um negócio devem ser projetadas e, se necessário, redesenhadas, para estarem conforme as necessidades dos clientes; identificação dos segmentos de mercado a serem atingidos; e mecanismo e maneira pela qual o valor deve ser capturado (Teece, 2007). O segundo componente é a seleção das fronteiras organizacionais e tem como objetivo a formação de capacidade para gerenciar complementos e plataformas, definindo o escopo de abrangência das atividades e as fronteiras da organização (Teece, 2007). Associado a essa capacidade está o terceiro componente, que são as rotinas para seleção de protocolos de tomada de decisões.

Segundo Teece (2007), a existência de capacidades dinâmicas está intimamente ligada às decisões sobre como alocar os recursos da organização. Os processos de tomada de decisão em organizações hierárquicas envolvem processos burocráticos, os quais englobam o compromisso e o balanceamento dos lados que envolvem a decisão, tornando o processo decisório lento e reforçando o status quo, criando um viés contrário à inovação. Por um lado, empresas que conseguem enxergar boas oportunidades muitas vezes falham em fazer o investimento necessário para aproveitá-las. Por outro lado, um otimismo excessivo também cria problemas, já que pode vir a permitir a existência de projetos com retornos baixos ou negativos. Assim, o autor defende a necessidade de existir um balanço no portfólio de investimentos da organização governado por protocolos de tomada de decisão que selecionem adequadamente os investimentos a serem feitos.

Por fim, o quarto componente da capacidade de aproveitar oportunidades refere-se às rotinas para construir lealdade e comprometimento. O comprometimento dos colaboradores pode, segundo Teece (2007), aumentar consideravelmente o desempenho da empresa.

A outra capacidade que fundamenta as capacidades dinâmicas é, também segundo Teece (2007), a capacidade de gerenciar ameaças e transformações. Ela é desenvolvida por meio de três componentes: (a) descentralização e decomposição; (b) coespecialização; (c) governança e gerenciamento do conhecimento.

Retomando Teece (2007), todo sistema possui subsistemas que, até certo ponto, são independentes e interdependentes. Ao mesmo tempo, é necessário entender que uma organização não conseguirá ter capacidade de responder às demandas de seus clientes e adotar novas tecnologias se houver um alto grau de centralização das decisões. Por isso, à medida em que as organizações crescem, é necessário que ocorra uma descentralização para evitar problemas de falta de flexibilidade e capacidade de resposta. Também é importante notar que a descentralização, embora benéfica, compromete a capacidade da organização para integrar. Trata-se de uma questão de equilíbrio: as unidades organizacionais necessitam de autonomia para tomar decisões rápidas, mas devem permanecer conectadas para serem coordenadas.

Outra habilidade gerencial importante consiste em identificar, desenvolver e utilizar uma combinação especializada e coespecializada de ativos. Desde seu artigo clássico sobre o papel dos ativos complementares no sucesso da comercialização da inovação (Teece, 1986), o autor tem enfatizado a importância de ativos coespecializados na sustentação da vantagem competitiva, já que não podem ser prontamente adquiridos por concorrentes. Estes constituem uma classe particular de ativos complementares em que o seu valor é função do uso conjunto com outros ativos especializados.

Por fim, torna-se chave ter uma forma de governança que contemple processos de integração de know how externo, aprendizagem, compartilhamento e integração de conhecimento. É uma estrutura de incentivos na sustentação das capacidades dinâmicas, principalmente quando os ativos intangíveis são críticos para o sucesso da organização. Igualmente importantes são os processos de monitoramento e gerenciamento de vazamento, roubo e mal uso de conhecimento, segredos industriais e outras propriedades intelectuais. A terceirização de produção e a proliferação de empreendimentos conjuntos (joint ventures) também constituem motivos para desenvolver procedimentos de governança de transferência de tecnologia e de propriedade intelectual. Outras questões de governança relacionadas com a habilidade da organização em obter combinações adequadas de ativos incluem o desenvolvimento do modelo de negócio apropriado, assim como incentivos para entendimento, alinhamento e resolução das questões de agência. 
A habilidade para integrar e combinar ativos, incluindo os de conhecimento, é fundamental no desenvolvimento dos processos de melhoria, que, segundo Zollo e Winter (2002), caracterizam as capacidades dinâmicas. Na visão desses autores, os processos de melhoria estão relacionados a um ciclo de evolução do conhecimento, o qual faz uso de três mecanismos de aprendizagem: (a) acumulação de experiência; (b) articulação de conhecimento; e (c) codificação do conhecimento.

A acumulação da experiência é feita por meio de rotinas, pois constituem a memória procedural da empresa (Cohen \& Bacadyan, 1994). As rotinas refletem a sabedoria da empresa, obtida por meio da experiência, na medida em que são "o resultado do aprendizado por tentativa e erro e a seleção e retenção de comportamentos anteriores" (Gavetti \& Levinthal, 2000, p. 113).

A articulação do conhecimento se dá a partir do compartilhamento de experiências individuais. Conforme assinalam Zollo e Winter (2002, p. 341), o esforço cognitivo dos membros da organização, direcionado para realçar o entendimento sobre as relações causais entre suas ações e o desempenho geral da empresa, melhora a competência organizacional. Por sua vez, a codificação do conhecimento consiste na documentação deste por meio de manuais, desenhos, planilhas, sistemas de suporte à decisão, software de gerenciamento de projetos ou qualquer outro meio que permita o armazenamento e a recuperação de informações.

A especificação desses mecanismos de aprendizagem consegue, segundo Zollo e Winter (2002), estabelecer como as capacidades dinâmicas e as rotinas operacionais evoluem com o tempo. Nesta perspectiva, os autores propõem uma sistematização do processo de desenvolvimento das capacidades dinâmicas a partir de um modelo evolucionário do conhecimento, em que o conhecimento organizacional segue um padrão evolutivo baseado no tripé variação - seleção - retenção do paradigma evolucionário clássico. O ciclo é composto de cinco fases (Figura 1):

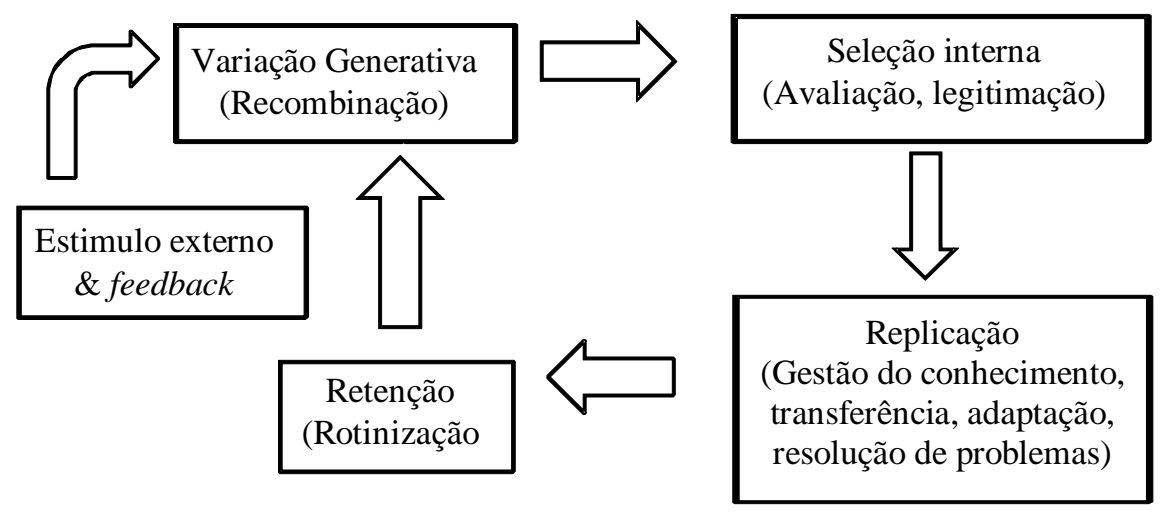

Figura 1. Etapas e Atividades do Ciclo de Evolução do Conhecimento.

Fonte: Zollo, M., \& Winter, S. G. (2002). Deliberate learning and the evolution of dynamic capabilities (p. 343). Organization Science, 13(3), 339-351. doi: 10.1287/orsc.13.3.339.2780

1. Um estímulo externo (ou feedback) gera a possibilidade de variação generativa para solução de um dado problema;

2. Essa variação de soluções passa então por um processo de seleção interna, no qual a solução será avaliada e legitimada;

3. Uma vez legitimada, ocorre uma fase de replicação do conhecimento, na qual existe transferência de conhecimento por meio de mecanismos de gestão do conhecimento, e, na qual, podem ocorrer adaptações para a resolução de problemas;

4. Uma vez replicada, a solução é rotinizada e, finalmente;

5. As rotinas sofrem variações ao longo do tempo e realimentam o processo de conhecimento. 
Outra proposta interessante de análise do desenvolvimento das capacidades dinâmicas é a de Wang e Ahmed (2007). O modelo dos autores (Figura 2) está baseado em duas premissas básicas: (a) as capacidades são construídas durante longo período de tempo; (b) o crescimento da organização ocorre de modo tradicional, por meio do acúmulo e do desenvolvimento de recursos internos e capacidades. A partir dessas premissas, os autores desenvolvem três proposições: (a) quanto mais dinâmico é o ambiente do mercado, mais forte é o direcionamento das empresas em exibir capacidades dinâmicas devido às mudanças externas; (b) quanto mais capacidades dinâmicas uma empresa demonstra, maior a probabilidade de construir capacidades particulares ao longo do tempo, sendo que o desenvolvimento de capacidades particulares é ditado pela estratégia da empresa; (c) as capacidades dinâmicas são condutoras de desempenho de longo prazo da empresa, mas trata-se de uma relação indireta, mediada pelo desenvolvimento de capacidades, que, por sua vez, é mediada pela estratégia da empresa. As capacidades dinâmicas estão mais propensas a criar um desempenho melhor quando capacidades particulares são desenvolvidas em linha com a escolha estratégica da empresa.

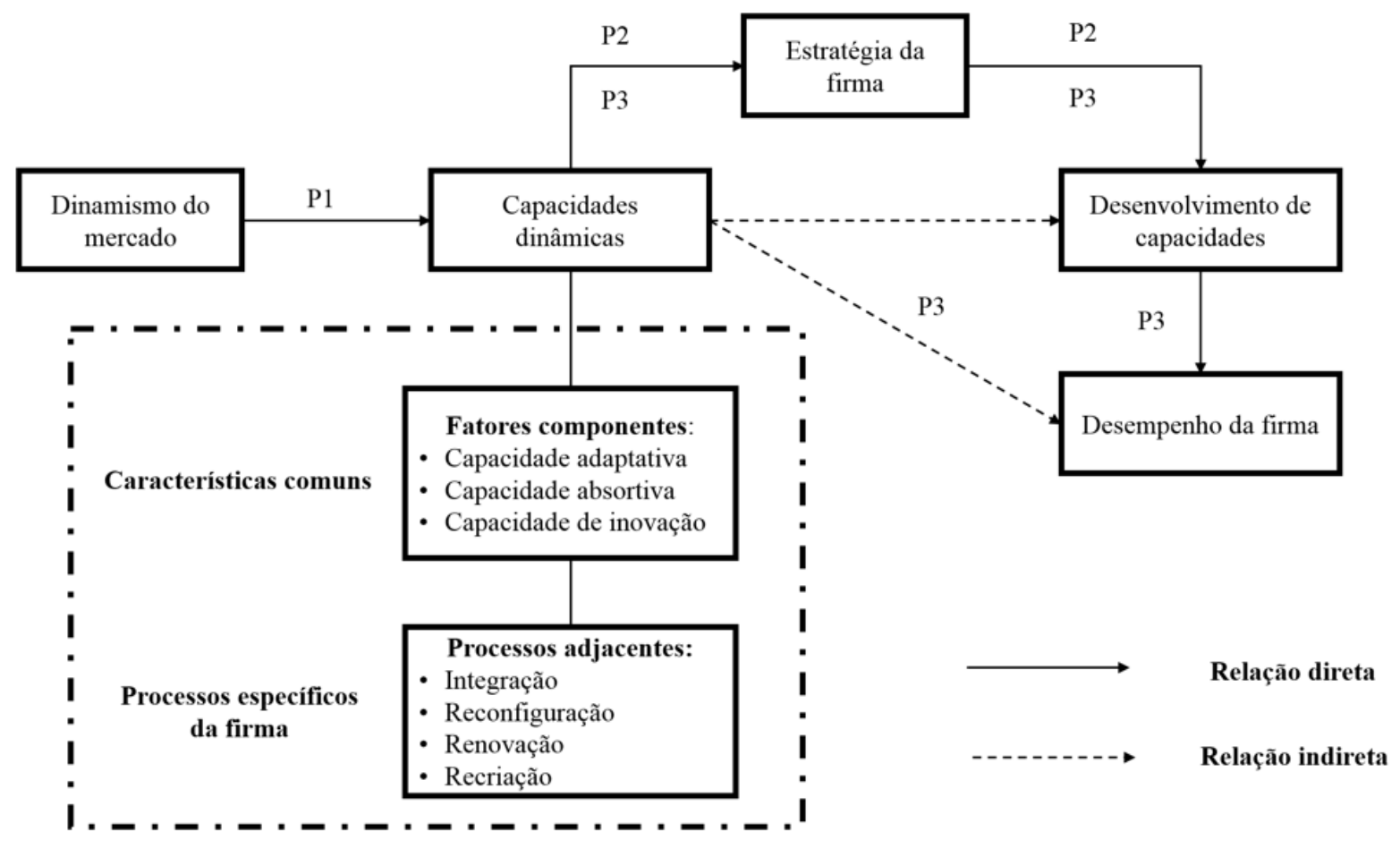

Figura 2. Modelo de Pesquisa de Capacidades Dinâmicas.

Fonte: Wang, C. L., \& Ahmed, P. K. (2007). Dynamic capabilities: a review and research agenda (p. 39). International Journal of Management Reviews, 9(1), 31-51. doi: 10.1111/j.1468-2370.2007.00201.x

O modelo proposto por Wang e Ahmed (2007) capta um aspecto importante defendido neste artigo, que é a ênfase nas especificidades da firma, expressas na estratégia e nos processos específicos de integração, reconfiguração, renovação e recriação de recursos e capacidades. Todavia, o modelo apresenta limitações, como a premissa de crescimento baseado somente nos recursos e nas capacidades internos. Conforme apontado por Eisenhardt e Martin (2000), a capacidade de forjar alianças e aquisições é um dos componentes das capacidades dinâmicas. Outrossim, os autores, na medida em que defendem proposições relativas ao desenvolvimento das capacidades ao longo do tempo, apontam para uma abordagem longitudinal, porém não indicam como tratar esse ciclo recursivo.

\section{Capacidades Dinâmicas: Uma Proposta de Síntese}

A partir do levantamento das várias definições de capacidades dinâmicas, nota-se que é possível sintetizar o conceito de capacidades dinâmicas como a capacidade que é baseada em decisões 
deliberadas e recorrentes, composta por processos combinatórios de capacidades que permitem criar, estender, modificar ou reconfigurar as capacidades-chave da organização e sua base de recursos e competências, fazendo uso de três elementos componentes: (a) comportamentos e habilidades; (b) rotinas e processos; (c) mecanismos de aprendizagem e governança do conhecimento.

Para que a empresa desenvolva capacidades dinâmicas, é necessário, em primeiro lugar, um conjunto de comportamentos e habilidades relacionadas à mudança e à inovação. Em termos de comportamento, destacam-se a lealdade e o comprometimento com a mudança (Andreeva \& Chaika, 2006; Teece, 2009). As habilidades envolvem: (a) identificar e capitalizar oportunidades de mercado, bem como reconhecer o valor das informações externas, assimilá-las e aplicá-las comercialmente (Wang \& Ahmed, 2007); (b) habilidades em desenvolver novas estratégias rapidamente (ou melhor) do que a concorrência, e habilidades de aprender a aprender (Collis, 1994); ou ainda (c) habilidades não específicas, não necessariamente conectadas com a execução da rotina operacional, como: comunicação, negociação, resolução de conflitos, liderança, análise econômica de ideias, resolução de problemas, gerenciamento de projetos e de pessoas (Andreeva \& Chaika, 2006).

Associado a essas habilidades e comportamentos, é necessária a existência de rotinas e processos de suporte à geração de novas ideias, novos produtos e serviços, bem como na seleção e na implementação da mudança (Teece, 2009).

$\mathrm{Na}$ literatura de capacidades dinâmicas, há autores que incluem, além dos processos, rotinas. Entretanto, conforme assinala Gerard (2009), rotinas, definidas como padrões de comportamento repetíveis, que conectam atores num dado contexto, são parte do processo. As rotinas são projetadas juntamente com o processo de trabalho ou podem emergir de forma independente na medida em que os atores encontrem meios mais eficazes de desempenhar suas tarefas. Quando as rotinas emergem, as organizações buscam monitorar as mudanças críticas e incorporar essas mudanças na estrutura existente.

De acordo com Gerard (2009), os processos contêm todas as capacidades necessárias para transformar entradas em resultados desejados. Isso inclui especificações, tecnologia, ferramentas, procedimentos, políticas, práticas e métodos. Os processos fornecem a estrutura de trabalho e as rotinas representam a execução dessa estrutura (Figura 3).

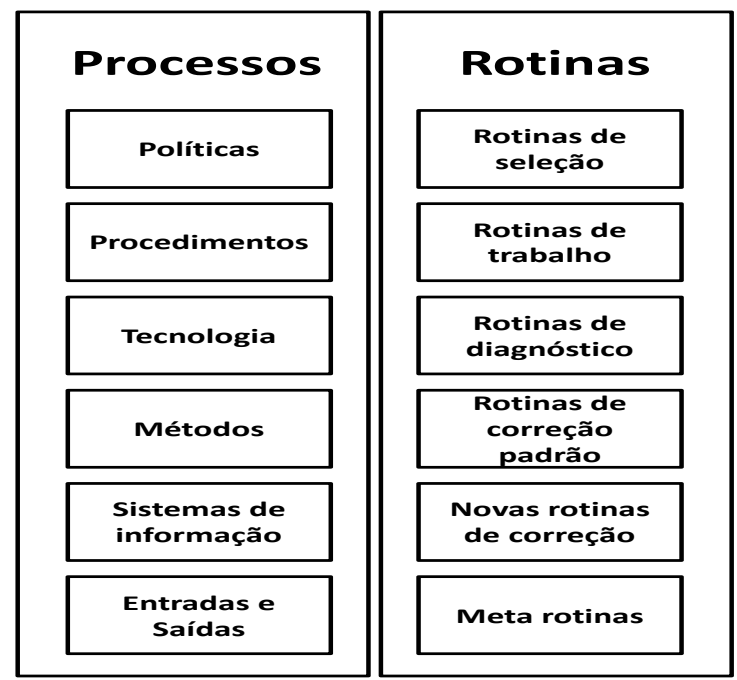

Figura 3. Processos $X$ Rotinas.

Fonte: Gerard, J. A. A (2009). Theory of organizational routines: development of a topology and identification of contextual determinants (p. 159). (Dissertation Thesis). ProQuest UMI Dissertation Publishing, Ann Arbor, Michigan.

Se a mudança não faz parte do repertório de rotinas da empresa, não há capacidades dinâmicas, mas sim soluções ad hoc (Winter, 2003). A capacidade dinâmica consiste num conjunto de atividades rotinizadas direcionadas para o desenvolvimento e a adaptação de rotinas operacionais, também denominadas de rotinas de busca (Winter, 2003), ou metarrotinas (Gerard, 2009). De acordo com Teece (2007), esses processos e rotinas incluem: (a) rotinas de desenvolvimento científico e tecnológico 
exógeno; (b) rotinas de identificação de segmentos de mercado alvo; (c) rotinas e processos de pesquisa e desenvolvimento; (d) processos e rotinas para delinear soluções para clientes com o respectivo modelo de negócios; (e) processos e rotinas para definir fronteiras da organização; (f) processos para definição e uso rotineiro de protocolos de tomada de decisões de investimento; (g) processo de descentralizar decisões por meio da decomposição de estruturas organizacionais; (h) processos de coespecialização de ativos; e (i) processos de solução do problema de agência e influência de grupos internos da empresa, e processos de descentralização das decisões. Além das rotinas de busca, é necessário desenvolver processos e rotinas relacionados aos hábitos e comportamentos, como as rotinas de alinhamento do sistema de recompensas (Andreeva \& Chaika, 2006) e as rotinas de construção de lealdade e comprometimento (Teece, 2009).

A importância de processos e rotinas faz com que a capacidade dinâmica seja o resultado de uma hierarquia de capacidades. No nível hierárquico inferior estão as capacidades funcionais (Collis, 1994) ou comuns (Wang \& Ahmed, 2007). No nível intermediário, as capacidades-chave, relacionadas a melhoramentos nos processos de negócio (Wang \& Ahmed, 2007), exploração e seleção de oportunidades (Teece, 2009). A capacidade dinâmica seria o terceiro nível, o criativo (Collis, 1994), ou capacidades superiores, que mudam o produto ou a escala e a base de consumidores (Winter, 2003).

Além das rotinas e processos, é necessário que a empresa desenvolva mecanismos de aprendizagem e governança do conhecimento que deem suporte à existência de capacidades dinâmicas. Ou seja, deve haver um ciclo contínuo de acumulação de experiência através de um processo recursivo que torna a empresa cada vez mais apta a desenvolver capacidades dinâmicas. Essa visão é defendida por Zollo e Winter (2002) com seu ciclo recursivo de evolução do conhecimento. Segundo esses autores, esses mecanismos incluem: desenvolvimento de diversas soluções possíveis para um dado problema; articulação do conhecimento por meio de discussões coletivas, sessões de esclarecimentos de dúvidas, processos de avaliação de desempenho; processos para acumulação de experiência e legitimação dos novos conhecimentos gerados.

Outros mecanismos organizacionais especiais são apontados por Andreeva e Chaika (2006), como: grupos de trabalhos multidisciplinares, comitês, delegação de responsabilidades, intensificação da troca de informações entre departamentos.

A partir desses elementos componentes das capacidades dinâmicas, é possível pensar na dinâmica efetivamente, ou seja, no modo como as capacidades se desenvolvem e se sustentam. Como se pode observar na Figura 4, a seguir, a reunião de comportamentos e habilidades de mudança e inovação, associada aos processos e às rotinas de suporte às capacidades dinâmicas, as quais são sustentadas por mecanismos de aprendizagem e governança do conhecimento, resultam em capacidades dinâmicas. As capacidades dinâmicas, sendo resultado deste conjunto de elementos e mecanismos de suporte, podem ser identificadas a partir de uma série de indicadores, como: geração de ideias e introdução de rupturas no mercado; mudanças organizacionais; inovação e desenvolvimento de novos mercados. 


\section{Elementos componentes}

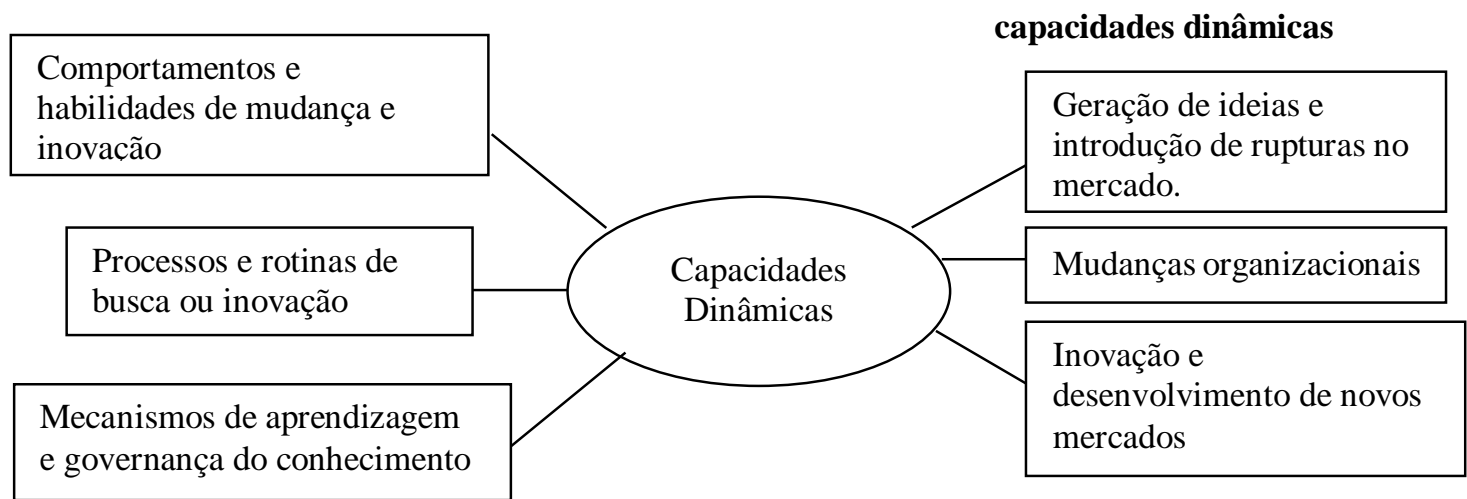

Figura 4. Modelo Integrado de Capacidades Dinâmicas: Comportamentos, Habilidades, Processos e Mecanismos de Aprendizagem e Governança do Conhecimento.

Fonte: Elaborada pelos autores.

Vale observar que este é um modelo conceitual. A operacionalização dos elementos componentes e o teste das relações entre estes fogem ao escopo do presente artigo. Mas, em princípio, é possível, a partir da reunião das contribuições apontadas pelos vários autores aqui selecionados, apontar as seguintes hipóteses de pesquisa:

1. Quanto maiores a lealdade e o comprometimento com a mudança, por meio de comunicações abertas, transparentes e diálogos francos, maior a probabilidade de desenvolvimento de capacidades dinâmicas na organização.

2. Quanto mais habilidades de geração de novas ideias, busca e seleção, maior a probabilidade de desenvolvimento de capacidades dinâmicas na organização.

3. Quanto mais habilidades não específicas (autoaprendizagem, comunicação, negociação, resolução de conflitos, liderança, análise econômica de ideias, apresentação de ideias, resolução de problemas, gerenciamento de projetos e pessoas), maior a probabilidade de desenvolvimento de capacidades dinâmicas na organização.

4. Quanto mais rotinas e processos de suporte à geração de novas ideias, novos produtos e serviços, bem como na seleção e na implementação de mudanças, maior a probabilidade de desenvolvimento de capacidades dinâmicas na organização.

5. Quanto mais rotinas e processos de suporte à tomada de decisão, de modo a promover a descentralização das decisões de investimento, maior a probabilidade de desenvolvimento de capacidades dinâmicas na organização.

6. Quanto mais mecanismos de estímulo à busca, à assimilação e à aplicação comercial de oportunidades de mercado, maior a probabilidade de desenvolvimento de capacidades dinâmicas na organização.

7. Quanto mais definida a estrutura de incentivos à solução do problema de agência e à influência de grupos internos da empresa, maior a probabilidade de desenvolvimento de capacidades dinâmicas na organização.

8. Quanto maior a exploração de mecanismos que promovam a replicação e a reconfiguração da base de conhecimento, inclusive a coespecialização de ativos, maior a probabilidade de desenvolvimento de capacidades dinâmicas na organização.

Esta proposta integradora implica uma série de conclusões que, de certa forma, respondem algumas das críticas feitas à abordagem de capacidades dinâmicas. Em primeiro lugar, a capacidade 
dinâmica envolve uma visão integrada da firma, portanto requer uma compreensão da mudança nos vários níveis de análise: individual, grupo (coletivo), e organizacional. Cada um dos elementos componentes aqui apontados refletem esta perspectiva multinível. No nível individual, encontram-se as habilidades e comportamentos de mudança. No nível coletivo e organizacional, situam-se os processos, rotinas e mecanismos de aprendizagem e governança do conhecimento. Nesse sentido, o construto capacidade dinâmica é eminentemente interdisciplinar e, reiterando as críticas feitas por alguns autores, como Arend e Bromiley (2009), não é uma abordagem nova, mas sim uma abordagem integradora.

Em segundo lugar, a capacidade dinâmica não pode ser confundida com o seu resultado e nem com o ambiente, visto ser ela mesma uma variável de resultado. Na verdade, os elementos determinantes da existência de capacidades dinâmicas são o conjunto de comportamentos, habilidades, rotinas, processos e mecanismos de aprendizagem e governança do conhecimento voltados para a mudança e a inovação. A articulação desses elementos pode resultar em graus variados de inovação e dinamismo, podendo se manifestar em ambientes de dinamismo variado, seja setores em que a inovação é mais intensa ou setores mais tradicionais, com tecnologia consolidada. Essa articulação é um indicativo que, num modelo de mensuração das capacidades dinâmicas, todos os indicadores são reflexivos.

E, por fim, em terceiro, a identificação das capacidades dinâmicas requer uma perspectiva histórica (estudos longitudinais). Nesse sentido, há espaço para o desenvolvimento de pesquisas baseadas numa abordagem de processo (Van de Ven, 1992, 2007), abordagem adotada por autores na área de mudança organizacional (Tsoukas \& Chia, 2002).

\section{Conclusão}

O artigo apresentou uma visão geral das definições que envolvem o constructo de Capacidades Dinâmicas de autores-chave no estudo do assunto. Com base nas definições apresentadas, foi definida uma classificação para capacidades dinâmicas divididas em duas visões. A primeira visão é definida como um conjunto de comportamentos, habilidades e capacidades organizacionais que, quando combinadas, criam capacidades dinâmicas na organização. A segunda visão define que capacidades dinâmicas são processos e rotinas que as organizações devem usar para poderem se adaptar e manter vantagens competitivas.

O trabalho também abordou os autores que discutem os mecanismos de suporte à existência de capacidades dinâmicas, baseados em um ciclo de acumulação de experiências e evolução da base de conhecimento numa organização.

Com base nas diferentes visões apresentadas pelos autores pesquisados, o artigo propôs uma definição do constructo capacidades dinâmicas fazendo uso de três elementos componentes: (a) comportamentos e habilidades; (b) rotinas e processos; (c) mecanismos de aprendizagem e governança do conhecimento.

A articulação destes elementos e mecanismos de suporte das capacidades dinâmicas resulta num modelo teórico em que vários aspectos relacionados à existência de capacidades dinâmicas, como inovação, geração de novas ideias e dinamismo do ambiente podem ou não estar presentes. Estes são apenas indícios de capacidades dinâmicas.

Como sugestão de pesquisas futuras, propõe-se a operacionalização de cada um destes componentes e o desenvolvimento de uma escala de capacidades dinâmicas. Vale observar que a operacionalização dos componentes das capacidades dinâmicas aqui apresentados, embora abordados de forma isolada, já está presente em vários trabalhos internacionais, principalmente em estudos que buscam identificar rotinas em processos de inovação ou de desenvolvimento de novos produtos, como é o caso de Salvato (2009) e Pavlou e El Sawy (2011). Todavia, é necessário ampliar o escopo de análise para uma melhor compreensão da manifestação de capacidades dinâmicas em contextos variados, seja setores mais dinâmicos do ponto de vista da inovação, seja outros mais tradicionais, com tecnologia 
consolidada. Nesse sentido, ainda há um extenso espaço para o desenvolvimento de pesquisas em capacidades dinâmicas, como pesquisa quantitativa ou qualitativa e estudos de caso.

No Brasil, em particular, as pesquisas em capacidades dinâmicas ainda são escassas, poucos são os trabalhos publicados em periódicos, em sua maioria sendo associados a recursos e competências, com preferência por abordagens qualitativas (Aragão, Forte, \& Oliveira, 2010). Em levantamento bibliométrico mais recente sobre a produção nacional em capacidades dinâmicas, com recorte nos periódicos nacionais da área de Administração e Turismo classificados entre os níveis A2 e B2 do WebQualis da Coordenação de Aperfeiçoamento de Pessoal de Nível Superior (CAPES), Picoli, Souza e Takahashi (2013) identificaram que apenas 19 artigos foram publicados no período de 1997 a 2012, sendo que, deste total, sete são ensaios teóricos. São artigos em sua maioria que apresentam o tema de capacidade dinâmica associado com outros temas, como cultura (Fleury, 2009; Maciel, Sato, \& Kato, 2012), recursos humanos (Brandão, Borges-Andrade, Puentes-Palacios, \& Laros, 2012), inovação (Burlamaqui \& Proença, 2003; Gonçalves, Brandão, \& Muniz, 2008; Pelaez, Melo, Hofmann, \& Aquino, 2008; Pitassi, 2012), estratégia (Monteiro, Silva, \& Ladeira, 2008; Muzzio, 2010), competências essenciais (Macedo-Soares \& Figueira, 2007), competência e aprendizagem organizacional (Leite \& Porsse, 2003), habilidades (Nobre, Tobias, \& Walker, 2011) e processo decisório (Carnasciali \& Delazari, 2011).

Enfim, falta avançar nas pesquisas sobre capacidade dinâmica, sobretudo do ponto de vista da análise dos seus elementos componentes, seja do ponto de vista de comportamentos, habilidades, rotinas, processos e mecanismos de aprendizagem e governança do conhecimento, voltados tanto para a inovação quanto para a mudança. Tais elementos, posto que desenvolvidos ao longo da trajetória organizacional, num processo cumulativo de conhecimento e aprendizagem, devem ser analisados numa perspectiva temporal e ou de processo, o que exige um esforço adicional de pesquisa.

\section{Referências}

Ambrosini, V., Bowman, C., \& Collier, N. (2009). Dynamic capabilities: an exploration of how firms renew their resource base. British Journal of Management, 20(S1), S9-S24. doi: 10.1111/j.14678551.2008.00610.x

Amit, R., \& Schoemaker, P. J. H. (1993). Strategic assets and organizational rent. Strategic Management Journal, 14(1), 33-46. doi: 10.1002/smj.4250140105

Andreeva, T., \& Chaika, V. (2006). Dynamic capabilities: what they need to be dynamic? [Working Paper, 10 (E)] St. Petersburg State University, São Petersburgo.

Aragão, L. A., Forte, S. H. A. C., \& Oliveira, O. V. de (2010). Visão baseada em recursos e capacidades dinâmicas no contexto brasileiro: a produção e a evolução acadêmica em dez anos de contribuições. Revista Eletrônica de Administração, 16(2), 373-396. Recuperado de http://seer.ufrgs.br/index.php/read/article/view/38853/25025

Arend, R. J., \& Bromiley, P. (2009). Assessing the dynamic capabilities view: spare change, everyone? Strategic Organization, 7(1), 75-90. doi: 10.1177/1476127008100132

Augier, M., \& Teece, D. J. (2008). Strategy as evolution with design: the foundations of dynamic capabilities and the role of managers in the economic system. Organization Studies, 29(8/9), 1187-1208. doi: 10.1177/0170840608094776

Barney, J. B. (1986). Organizational culture: can it be a source of sustained competitive advantage? The Academy of Management Review, 11(3), 656-665. doi: 10.5465/AMR.1986.4306261 
Barney, J. B., \& Hesterly, W. S. (2011). Administração estratégica e vantagem competitiva (3a ed.). São Paulo: Pearson Prentice Hall.

Barreto, I. (2010). Dynamic capabilities: a review of past research and an agenda for the future. Journal of Management, 36(1), 256-280. doi: 10.1177/0149206309350776

Brandão, H. P., Borges-Andrade, J. E., Puente-Palacios, K., \& Laros, J. A. (2012). Relationships between learning, context and competency: a multilevel study. Brazilian Administration Review, 9(1), 1-22. Retrieved from http://www.scielo.br/pdf/bar/v9n1/a02v9n1.pdf. doi: 10.1590/S180776922012000100002

Burlamaqui, L., \& Proença, A. (2003). Inovação, recursos e comprometimento: em direção a uma teoria estratégica da firma. Revista Brasileira de Inovação, 2(1), 79-110.

Bygdas, A. L. (2006, July). Enacting dynamic capabilities in distributed organisational environments. Proceedings of the EGOS Conference, Bergen, Norway, 22.

Carnasciali, A. M. S. dos, \& Delazari, L. S. (2011). A localização geográfica como recurso organizacional: utilização de sistemas especialistas para subsidiar a tomada de decisão locacional do setor bancário. Revista de Administração Contemporânea, 5(1), 103-125. Recuperado de http://www.scielo.br/pdf/rac/v15n1/v15n1a07.pdf. doi: 10.1590/S1415-65552011000100007

Cohen, M. D., \& Bacadyan, P. (1994). Organizational routines are stored as procedural memory: evidence from a laboratory study. Organizational Science, 5(4), 554-568. doi: $10.1287 /$ orsc.5.4.554

Collis, D. J. (1994). Research note: how valuable are organizational capabilities? Strategic Management Journal, 15(Suppl.), 143-152. doi: 10.1002/smj.4250150910

Cyert, R., \& March, J. G. (1963). A behavioral theory of the firm. Prentice Hall: Englewood Cliffs.

Dosi, G., Faillo, M., \& Marengo, L. (2008). Organizational capabilities, patterns of knowledge accumulation and governance. Organization, 29(8/9), 1164-1185. doi: $10.1177 / 0170840608094775$

Dosi, G., Nelson, R. R., \& Winter, S. G. (2000). Introduction: the nature and dynamics of organizational capabilities. In G. Dosi, R. Nelson, \& S. G. Winter (Eds.), The nature and dynamics of organisational capabilities (pp. 12-33). Oxford: Oxford Press.

Eisenhardt, K. M., \& Martin, J. A. (2000). Dynamic capabilities: what are they? Strategic Management Journal, 21(10/11), 1105-1121. doi: 10.1002/1097-0266(200010/11)21:10/11<1105::AIDSMJ133>3.0.CO;2-E

Fleury, M. T. L. (2009). Organizational culture and the renewal of competences. Brazilian Administration Review, 6(1), 1-14. Retrieved from http://www.scielo.br/pdf/bar/v6n1/v6n1a02.pdf. doi: 10.1590/S1807-76922009000100002

Gavetti, G., \& Levinthal, D. (2000). Looking forward and look backward: cognitive and experiential search. Administration Science Quarterly, 45(1), 113-137. doi: 10.2307/2666981

Gerard, J. A. A (2009). Theory of organizational routines: development of a topology and identification of contextual determinants (Dissertation thesis). ProQuest UMI Dissertation Publishing, Ann Arbor, Michigan.

Gonçalves, C. A., Brandão, E. A., \& Muniz, R. M. (2008). A inovação e o design estético na geração de capacidades dinâmicas: um estudo de caso BTOB. PRETEXTO, 9(2), 9-38. 
Grant, R. (1991). The resource-based theory of competitive advantage: implications for strategy formulation. California Management Review, 33(3), 114-135.

Hayes, R., Wheelwright, S., \& Clark, K. (1988). Dynamic manufacturing: creating the learning organization. New York: Free Press.

Helfat, C. E., Finkelstein, S., Mitchell, W., Peteraf, M., Singh, H., Teece, D., \& Winter, S. G. (Eds.). (2007). Dynamic capabilities: understanding strategic changes in organizations. Malden, MA: Blackwell Publishing.

Helfat, C. E., \& Peteraf, M. A. (2003). The dynamic resource-based view: capability lifecycles. Strategic Management Journal, 24(10), 997-1010. doi: 10.1002/smj.332

Helfat, C. E., \& Peteraf, M. A. (2009). Understanding dynamic capabilities: progress along a developmental path. Strategic Organization, 7(1), 91-102. doi: 10.1177/1476127008100133

Helfat, C. E., \& Winter, S. G. (2011). Untangling dynamic and operational capabilities: strategy for the (n)ever-changing world. Strategic Management Journal, 32(11), 1243-1250. doi: $10.1002 / \mathrm{smj} .955$

Leite, J. B. D., \& Porsse, M. C. de (2003). Competição baseada em competências e aprendizagem organizacional: em busca da vantagem competitiva [Edição Especial]. Revista de Administração Contemporânea, 7, 121-141. doi: 10.1590/S1415-65552003000500007

Leonard-Barton, D. (1992). Core capabilities and core rigidities: a paradox in managing new product development [Special Issue]. Strategic Management Journal, 13, 111-125. doi: 10.1002/smj.4250131009

Lin, Y., \& Wu, L.-Y. (2014). Exploring the role of dynamic capabilities in firm performance under the resource-based view framework. Journal of Business Research, 67(3), 407-413. doi: 10.1016/j.jbusres.2012.12.019

Macedo-Soares, T. D. L. V. A., \& Figueira, L. A. P. A. (2007). Gestão estratégica da energia nucleoelétrica no Brasil: recursos e competências críticos para seu sucesso [Edição Especial]. Revista de Administração Contemporânea, 11, 55-76. doi: 10.1590/S1415-65552007000500004

Maciel, C. O. de, Sato, K. H., \& Kato, H. T. (2012). Capacidades dinâmicas e rituais de interação entre alta e média gerência: proposta de um framework. Revista de Administração Pública, 46(2), 599619. doi: 10.1590/S0034-76122012000200012

Makadok, R. (2001). Toward a synthesis of the resource-based and dynamic capability views of rent creation. Strategic Management Journal, 22(5), 387-401. doi: 10.1002/smj.158

McKelvie, A., \& Davidsson, P. (2009). From resource base to dynamic capabilities: an investigation of new firms. British Journal of Management, 20(Suppl.), S63-S80. doi: 10.1111/j.14678551.2008.00613.x

Monteiro, C. S. M. R. do, Silva, B. R., \& Ladeira, R. (2008). Estratégias no varejo de alimentos: um estudo com análise fatorial e de clusters. Revista Gestão e Planejamento, 9(2), 178-198.

Muzzio, H. (2010). A legitimidade cultural local nas práticas estratégicas de PMES. PRETEXTO, 11(2), $80-94$.

Nelson, R. R. (1991). Why do firms differ, and how does ite matter? Strategic Management Journal, 12(S2), 61-74. doi: 10.1002/smj.4250121006

Nelson, R. R., \& Winter, S. G. (1982). An evolutionary theory of economic change. Cambridge: Belknap Press. 
Nobre, F. S., Tobias, A. M., \& Walker, D. S. (2011). Uma visão da empresa baseada em habilidades: contextos estratégicos e contingenciais. Revista de Administração Contemporânea, 15(3), 413432. Recuperado de http://www.scielo.br/pdf/rac/v15n3/v15n3a04.pdf. doi: 10.1590/S141565552011000300004

Oxford University Press. (2010). New Oxford American dictionary. Oxford: Author.

Pavlou, P. A. \& El Sawy, O. A. (2011). Understanding the elusive black box of dynamic capabilities. Decision Sciences Journal, 42(1), 239-273. doi: 10.1111/j.1540-5915.2010.00287.x

Pelaez, V., Melo, M., Hofmann, R., \& Aquino, D. (2008). Fundamentos e microfundamentos da capacidade dinâmica da firma. Revista Brasileira de Inovação, 7(1), 101-125.

Penrose, E. (2006). Teoria do crescimento da firma (T. Szmrecsany, Trad.). Campinas: Unicamp. (Obra original publicada em 1959).

Peteraf, M. A. (1993). The cornestones of competitive advantage: a resource-based view. Strategic Management Journal, 14(3), 179-191. doi: 10.1002/smj.4250140303

Picoli, F. R., Souza, C. P. S, \& Takahashi, A. R. W. (2013, setembro). Produção nacional em capacidades dinâmicas: um estudo bibliométrico. Anais do Encontro Nacional da Associação Nacional de Pós-Graduação e Pesquisa em Administração, Rio de Janeiro, RJ, Brasil, 37.

Pitassi, C. (2012). Inovação aberta na perspectiva das empresas brasileiras de base tecnológica: proposta de articulação conceitual. Revista de Administração e Inovação, 9(3), 77-102. doi: 10.5773/rai.v9i3.678

Prahalad, C. K., \& Hamel, G. (1990). The core competence of the corporation. Harvard Business Review, 68(3), 79-91

Rumelt, R. P. (1984). Toward a strategic theory of the firm. In R. B. Lamb (Ed.), Competitive strategic management (pp. 556-570). Englewood Cliffs, NJ: Prentice-Hall.

Salvato, C. (2009). Capabilities unveiled: the role of ordinary activities in the evolution of product development processes. Organization Science, 20(2), 384-409. doi: 10.1287/orsc.1080.0408

Schumpeter, J. A. (1942). Capitalism, socialism, and democracy. New York: Harper.

Stefano, G. D., Peteraf, M., \& Verona, G. (2010). Dynamic capabilities deconstructed: a bibliographic investigation into the origins, development, and future directions of the research domain. Industrial and Corporate Change, 19(4), 1187-1204. doi: 10.1093/icc/dtq027

Teece, D. J. (1976). The multinational corporation and the resource cost of international technology transfer. Cambridge, MA: Ballinger.

Teece, D. J. (1986). Profiting from technological innovation: implications for integration, collaboration, licensing and public policy. Research Policy, 15(6), 285-305. doi: 10.1016/0048-7333(86)90027-2.

Teece, D. J. (1988). Technological change and the nature of the firm. In G. Dosi, C. Freeman, R. Nelson, G. Silverberg, \& L. Soete (Eds.), Technical change and economic theory (pp. 256-281). New York: Pinter Publishers.

Teece, D. J. (2007). Explicating dynamic capabilities: the nature and microfoundations of (sustainable) enterprise performance. Strategic Management Journal, 28(13), 1319-1350. doi: $10.1002 / \mathrm{smj} .640$

Teece, D. J. (2009). Dynamic capabilities \& strategic management. Oxford: Oxford University Press. 
Teece, D. J., \& Pisano, G. (1994). The dynamics capabilities of firms: an introduction. Industrial and Corporate Change, 3(3), 537-556. doi: 10.1093/icc/3.3.537-a

Teece, D. J., Pisano, G., \& Shuen, A. (1997.). Dynamic capabilities and strategic management. Strategic Management Journal, 18(7), 509-533. doi: 10.1002/(SICI)1097-0266(199708)18:7<509::AIDSMJ882>3.0.CO;2-Z

Teece, D. J., Rumelt, R., Dosi, G., \& Winter, S. (1994). Understanding corporate coherence: theory and evidence. Journal of Economic Behavior and Organization, 23(1), 1-30. doi: 10.1016/01672681(94)90094-9

Tsoukas, H., \& Chia, R. (2002). On organizational becoming: rethinking organizational change. Organization Science, 13(5), 567-582. doi: 10.1287/orsc.13.5.567.7810

Van de Ven, A. H. (1992). Suggestions for estudying strategy process: a research note. Strategic Management Journal, 13(S1), 169-188. doi: 10.1002/smj.4250131013

Van de Ven, A. H. (2007). Engaged scholarship: a guide for organizational and social research. Oxford: Oxford University Press.

Vogel, R., \& Güttel, W. H. (2013). The dynamic capability view in strategic management: a bibliometric review. International Journal of Management Reviews, 15(4), 426-446. doi: 10.1111/ijmr.12000

Wang, C. L., \& Ahmed, P. K. (2007). Dynamic capabilities: a review and research agenda. International Journal of Management Reviews, 9(1), 31-51. doi: 10.1111/j.1468-2370.2007.00201.x

Wernerfelt, B. (1984). A resource-based view of the firm. Strategic Management Journal, 5 (2), 171180.

Winter, S. G. (1964). Economic 'natural selection' and the theory of the firm. Yale Economic Essays, 4, 225-272.

Winter, S. G. (2003). Understanding dynamic capabilities. Strategic Management Journal, 24(10), 991995. doi: $10.1002 / \mathrm{smj} .318$

$\mathrm{Wu}$, L.-Y. (2010). Applicability of the resource-based and dynamic-capability views under environmental volatility. Journal of Business Research, 63(1), 27-31. doi: 10.1016/j.jbusres.2009.01.007

Zahra, S. A., Sapienza, H. J., \& Davidson, P. (2006). Entrepreneurship and dynamic capabilities: a review, model and research agenda. Journal of Management Studies, 43(4), 917-955. doi: 10.1111/j.1467-6486.2006.00616.x

Zollo, M., \& Winter, S. G. (2002). Deliberate learning and the evolution of dynamic capabilities. Organization Science, 13(3), 339-351. doi: 10.1287/orsc.13.3.339.2780 